\title{
O USO DA METODOLOGIA BIM NA GESTÃO DE INSTALAÇÕES: O CASO DA UNIVERSIDADE FEDERAL DO CEARÁ
}

\author{
Luciano Sousa $^{(1)}$, Sabrina Gonçalves ${ }^{(1)}$, Camily Barbosa ${ }^{(1)}$ \\ (1) Universidade Federal do Ceará, Fortaleza
}

\section{Resumo}

Na Universidade Federal do Ceará (UFC), as atividades de manutenção e operação das edificações são realizadas pela Superintendência de Infraestrutura e Gestão Ambiental, que é responsável por realizar o levantamento anual de todos os bens que compõem o patrimônio da universidade, relacionando ao estado de conservação e a necessidade de reforma ou substituição. Atualmente, isso é feito de forma pouco eficiente, na qual as informações acerca de um determinado ambiente ou bem são documentadas e repassadas ao setor responsável pela execução da manutenção. Esse procedimento, além de demandar mais tempo e ser suscetível a falhas, põe em risco o objetivo primordial de garantir a eficiência da infraestrutura física que permita a realização das atividades institucionais. Diante disso, foi elaborada uma solução para automatizar essas atividades e integrar as informações recebidas por meio da tecnologia Business Intelligence, que baseia-se na transformação de dados em informações, depois em decisões e finalmente em ações Turban (2009), aliando isso à tecnologia BIM que segundo Kymmell (2008) é projeto e processo de simulação, consiste em modelos tridimensionais, nos quais os componentes da construção trazem links para todas as informações necessárias nos projetos de planejamento, de construção ou de exploração e até de demolição. Espera-se, com isso, fornecer suporte aos gestores na tomada de decisões de forma fácil e intuitiva. A metodologia utilizada inicia com a modelagem parametrizada da edificação em análise, da qual são extraídas informações acerca de ambientes e bens que serão direcionadas a um banco de dados que será atualizado com o auxílio de um aplicativo desenvolvido pelo Escritório de Projetos Integrados de Engenharia (EPE). Por meio disso, é possível realizar o controle dos bens da universidade, melhorando a assertividade do planejamento financeiro relacionado aos custos de operação e manutenção e assegurando o bom desempenho das atividades afins a UFC.

\section{Introdução}

Para assegurar a funcionalidade da edificação ao longo de seu ciclo de vida, é imprescindível atentar às etapas de construção, mas também à forma como é feita a operação e a manutenção. 
O ciclo de vida do edifício é bastante longo, da ordem de décadas, perpassando pela concepção e promoção do empreendimento, pelos diversos projetos de especialidades, construção, uso e manutenção e, por fim, demolição ou reabilitação [1] (Figura 01). Fatores como programação de manutenção, estimativa de custos ao longo da vida útil e necessidade de se construir edificações mais duráveis (com maior vida útil) devem ter maior importância nos projetos e gerenciamento de empreendimentos, considerando também o custo do ciclo de vida (CCV). Em suma, é necessário melhorar a qualidade das edificações produzidas.

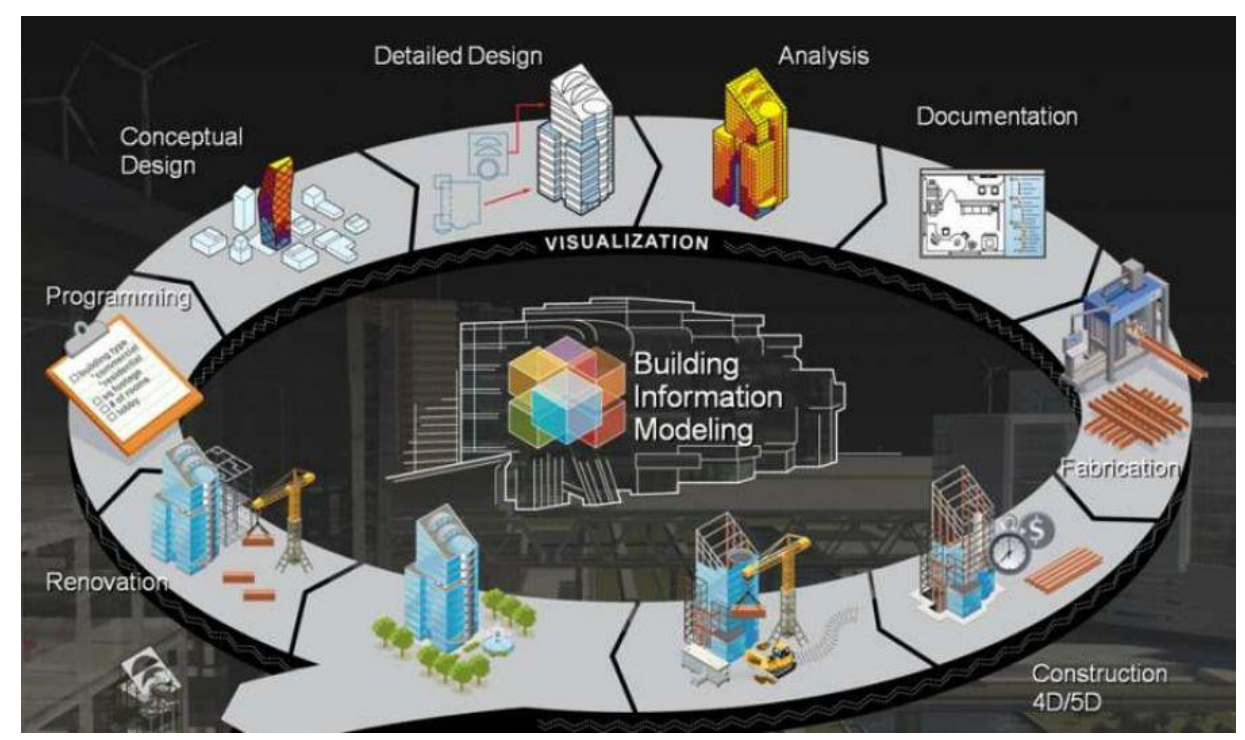

Figura 1: Ciclo de vida de uma edificação. Fonte: https://www.bimexperts.com.br/post/o-quee-bim.

Nesse contexto, a gestão de instalações corresponde a gestão ativa e coordenada de serviços de suporte de uma organização, considerando os recursos humanos e a organização da edificação (incluindo seus sistemas, plantas, equipamentos, alocações e mobília) necessários para que a organização atinja seus objetivos estratégicos de maneira eficiente [2]. Uma gestão eficiente é primordial para minimizar custos com reparos e detectar patologias e outros problemas que possam comprometer o desempenho da estrutura. Nesse tocante, a gestão das instalações realizada pela Universidade Federal do Ceará (UFC) atualmente ocorre de forma reativa, ou seja, a manutenção de um determinado bem só é realizada a partir de uma demanda que parte de estudantes, de professores ou de outros servidores. Dessa forma, a comunidade acadêmica solicita um determinado reparo, em seguida essa solicitação é analisada no que diz respeito ao custo e à relevância e, a partir disso, é tomada a decisão de se atender ou não à solicitação.No tocante à gestão de patrimônio, tem-se um procedimento separado da gestão de manutenção. Desse modo, existe um documento com informações acerca de todos os bens pertencentes à UFC, o qual é atualizado semestralmente por um funcionário responsável por determinado setor da universidade, que é encarregado de informar ao setor de patrimônio o estado o qual se encontra o bem. Dado o modo como esses procedimentos são realizados na universidade, percebeu-se que seria interessante que houvesse uma integração entre os setores, que permitiria ter um modelo unificado com as informações dos patrimônios e das edificações onde eles estão inseridos a fim de deixar o processo mais eficiente e possibilitar a previsão da manutenção 
preventiva, em contrapartida ao procedimento reativo realizado atualmente, uma vez que no modelo unificado haveria informações e geometrias suficientes para isto.

Partindo dessas questões, a metodologia BIM permitiria a melhor visualização de uma determinada edificação, bem como a posse de dados acerca de materiais e quantidades, por exemplo. BIM é a simulação de um projeto, que consiste na modelagem 3D dos componentes do mesmo, agregando-se toda a informação requerida ao seu planejamento, à construção ou operação, e ao encerramento do ciclo de vida da edificação [3]. Essa simulação, somada ao suporte da tecnologia Business Intelligence, que baseia-se na transformação de dados em informações, depois em decisões e finalmente em ações [4], permitiria uma gestão mais eficiente e tomadas de decisões mais assertivas e coerentes com a realidade da universidade e com as reais necessidades de suas instalações. O uso de modelos BIM para Operação e Manutenção $(\mathrm{O} \& \mathrm{M})$ é uma forma de analisar o comportamento e deterioração do edifício ao longo do tempo, fornecendo informações sobre o estado atual da edificação, além de seu histórico de manutenção e reformas anteriores [5]. Dessa forma, o objetivo do presente artigo é apresentar uma proposta para uma gestão dos edifícios da Universidade Federal do Ceará com o auxílio da tecnologia Business Intelligence concomitantemente com o BIM, de modo a tornar o processo mais prático e eficiente.

\section{Metodologia}

Inicialmente foi realizado um levantamento com o setor responsável da Universidade Federal do Ceará, sobre quais informações seriam relevantes no modelo BIM, para fins de operação e manutenção. Em seguida, foi realizado um levantamento de informações projetuais do edifício de uma das unidades didáticas (Bloco 707) para servir de piloto do processo. Assim, foi gerado um modelo paramétrico, com foco nas informações previamente estabelecidas e, com isso, foi possível gerar uma planilha de quantitativos a partir das informações contidas no modelo. Essas informações foram armazenadas em um banco de dados online. Diante disso, foi possível realizar a atualização dessas informações, de forma rápida. Com os dados armazenados, foi utilizada a ferramenta Power BI, para sintetizar os dados, gerar relatórios para que o gestor verifique de forma ágil e prática se é necessária intervenção em alguma parte da edificação e qual a previsão de custo para tal.

\section{Resultados}

\subsection{Modelagem 3D}

A partir do projeto fornecido pela UFCinfra e com a análise do bloco construído foi possível realizar a modelagem arquitetônica as built do Bloco 707, com informações parametrizadas e com o auxílio de programação visual, o qual serviu como piloto para a aplicação da metodologia proposta neste artigo. Para isso foram utilizadas algumas informações que seriam úteis para a equipe da gestão da universidade que realiza as manutenções das edificações, como mostra a Figura 02 abaixo, como custo, localização e estado de preservação de acordo com a necessidade. O método construtivo utilizado foi baseado na análise de dados necessários para ter uma gestão de patrimônio eficiente. Dessa forma, buscou-se separar os tipos de paredes por 
revestimento interno e externo a fim de que fosse possível separar por ambientes os dados estabelecidos, como área e data da última manutenção.

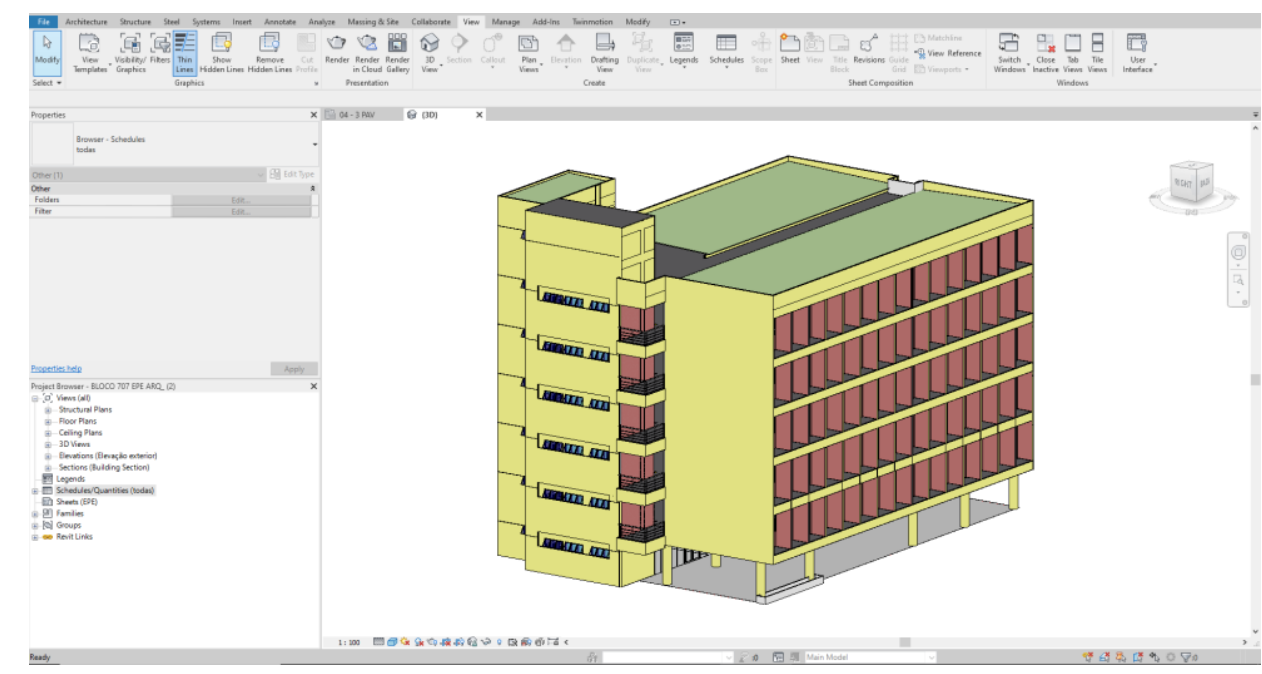

Figura 2: Bloco 707 do Centro de Tecnologia da Universidade Federal do Ceará.

Para automatizar o processo, foi criada uma rotina no Dynamo da Autodesk, que preenche os parâmetros dos componentes do modelo de forma automática, conforme a Figura 03.

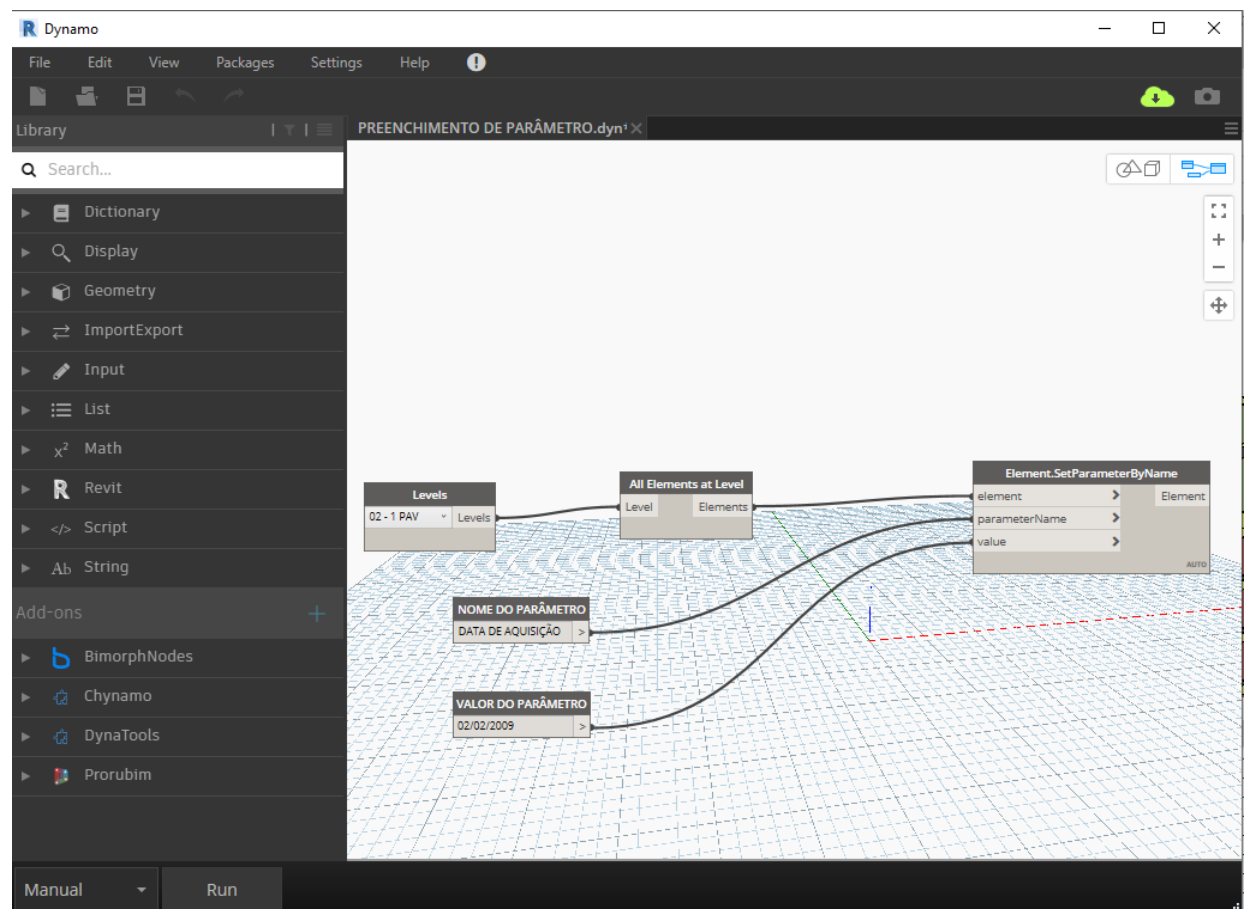

Figura 3: Rotina para preenchimento de parâmetros automáticos.

Para possibilitar a extração dos quantitativos foi necessário organizar tabelas de informações, para cada tipo de componente da edificação, como, paredes, janelas, portas, revestimentos e etc, conforme a figura abaixo. 


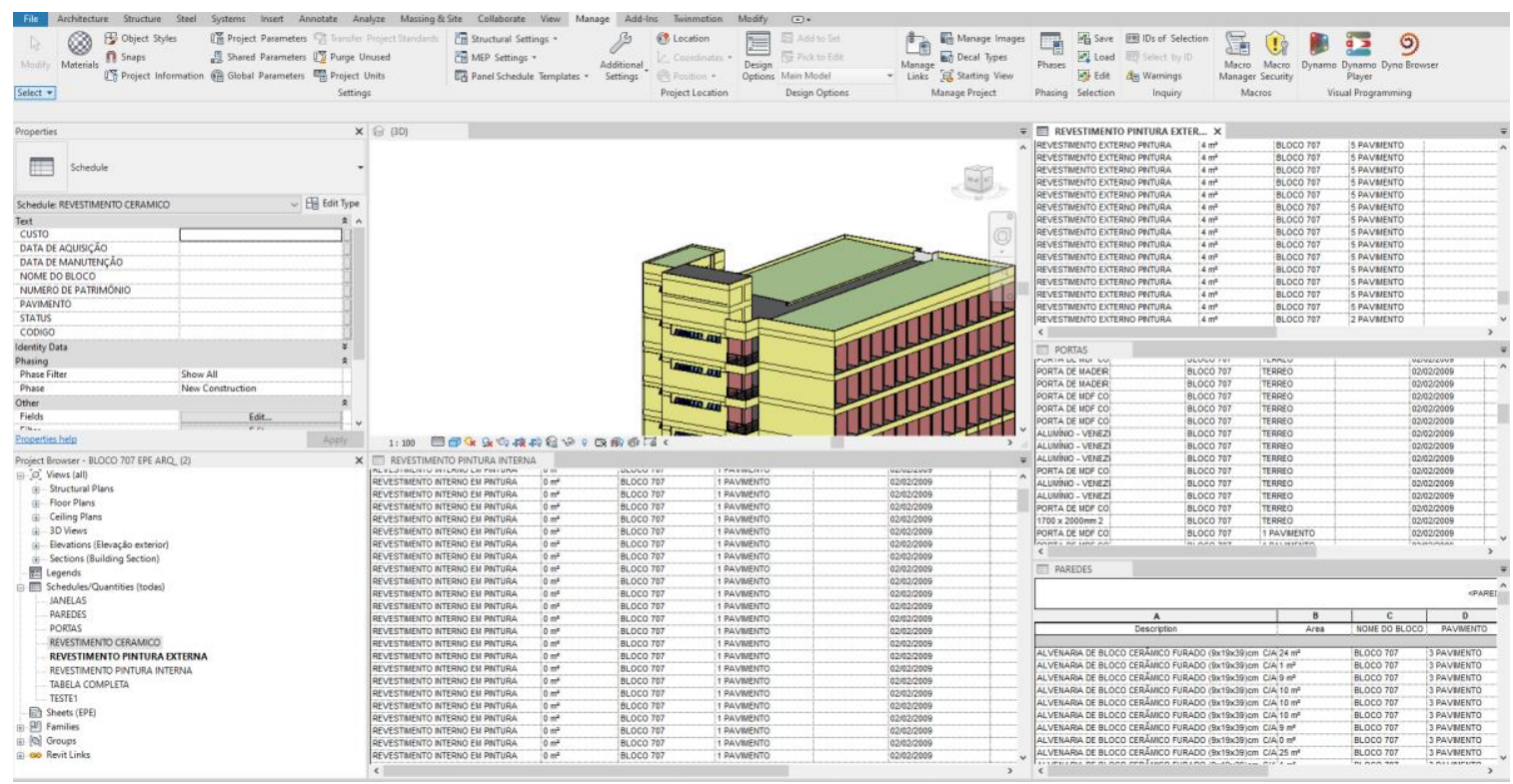

Figura 4: Bloco 707 do Centro de Tecnologia da Universidade Federal do Ceará.

\subsection{Quantitativos e estimativa de custos}

O orçamento de obras possui diversas aplicações, tais como, levantamento dos materiais e serviços, obtenção de índices para acompanhamento, dimensionamento de equipes, capacidade de revisão de valores e índices, realização de simulações, geração de cronogramas físico e financeiro, análise da viabilidade econômico-financeira [6]. Nesse cenário, se faz interessante criar a integração entre o modelo BIM e o orçamento, servindo de subsídio para tomada de decisões, sobretudo levando em conta a gestão financeira no setor responsável da universidade. Para tanto, com o auxílio da ferramenta de programação visual, foi possível realizar a extração dos quantitativos de forma automática, com a ferramenta Dynamo, conforme Figura 05, para uma planilha eletrônica, onde os dados foram configurados, organizados e salvos em um servidor em nuvem.

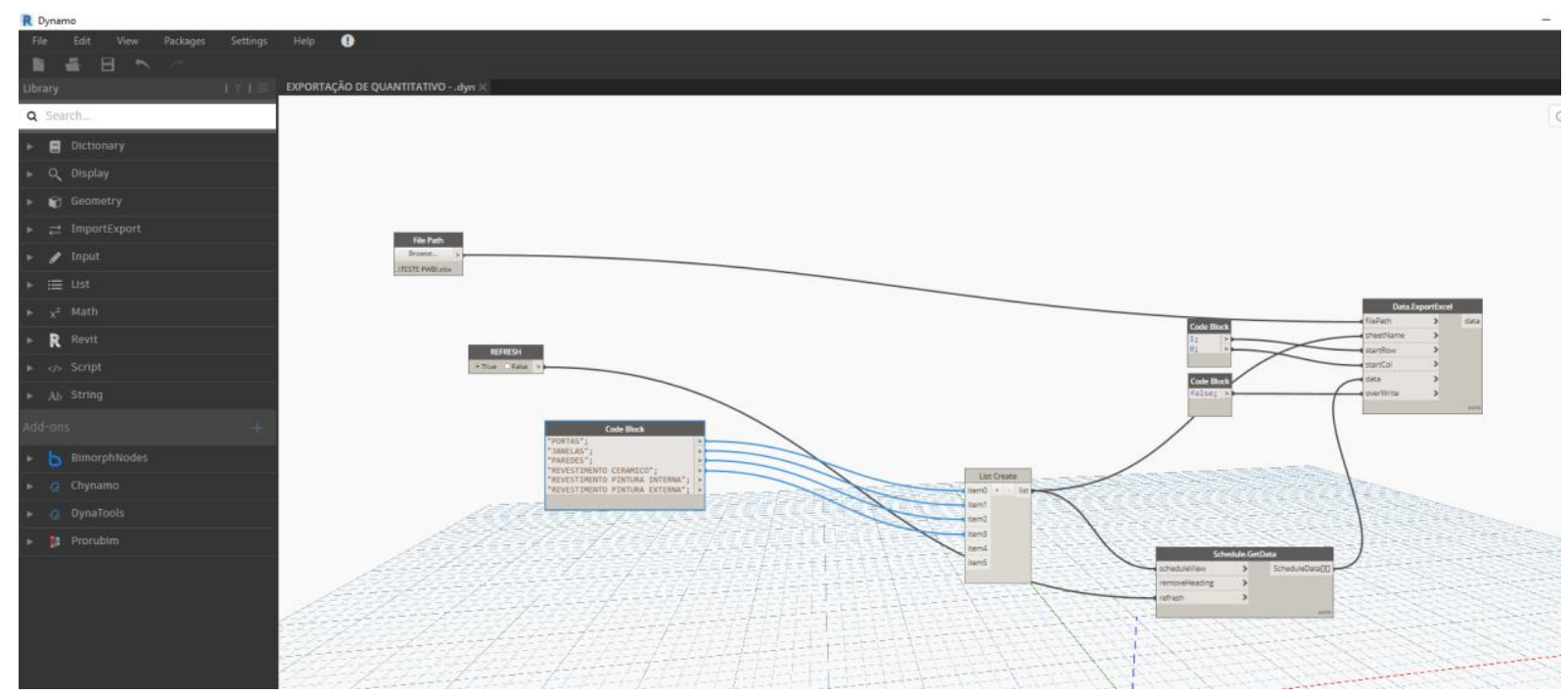

Figura 5: Rotina Dynamo para a extração de quantitativos. 
Em seguida esta planilha foi vinculada ao aplicativo Power BI para tratamento dos dados e melhorias de visualizações, onde se tornou possível filtrar e gerar gráficos automaticamente, conforme a Figura 06, melhorando o entendimento das informações pelo gestor que pode acessar as informações de qualquer lugar, de maneira mais organizada e visual, o que auxilia na tomada de decisões sem precisar ter uma ferramenta específica para isto, bastando acessar um endereço do servidor.

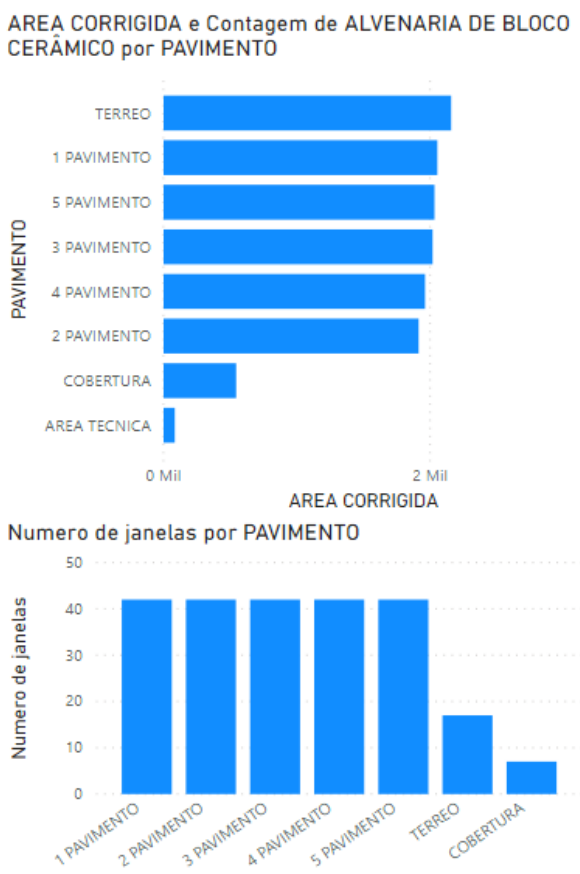

PAVIMENTO
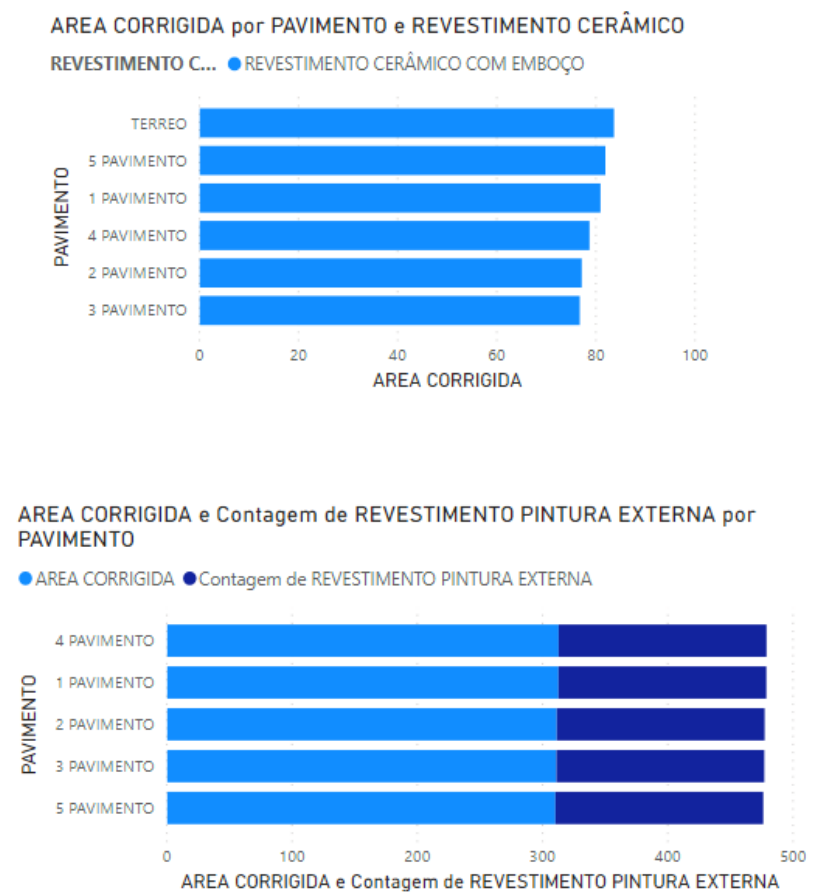

Figura 6: Gráficos gerados Power BI.

\section{Considerações finais}

Diante do exposto observa-se que há uma melhora no processo de gestão de facilities realizado na Universidade Federal do Ceará, pois a partir do projeto desenvolvido é possível realizar a previsão das manutenções preventivas de forma eficiente, auxiliando ainda na elaboração de orçamentos. A metodologia desenvolvida seria a solução para que os reparos e manutenções fossem feitos de maneira preventiva, de modo que certos inconvenientes fossem evitados devido a manutenção regular, diferente de como acontece atualmente, onde as manutenções são realizadas apenas após gerar incômodo na comunidade acadêmica. Além disso, a metodologia proposta permite unir informações de patrimônio com informaçõe da própria edificação, tornando o processo mais eficiente e permitindo uma visão completa do funcionamento da edificação. Ademais, , apesar do projeto ter sido desenvolvido em um único bloco, é possível que ele seja replicado e expandido para as demais edificações e que seja alterado os dados conforme as necessidades.

Dessa forma, pode-se considerar que o projeto piloto, apesar de não ter sido aplicado ainda, é de grande importância, pois propõe uma maneira inovadora de fazer a gestão das instalações, 
com o intuito de otimizar tempo e facilitar a tomada de decisões. Diante disso, recomenda-se que seja realizado um estudo de caso com aplicações reais a fim de que se obtenha feedback dos gestores das instalações para verificar a necessidade de adaptações e melhorias no projeto desenvolvido.

\section{Referências}

[1] FABRICIO, M. M., MELHADO, S. B. Projeto simultâneo e a qualidade ao longo do ciclo de vida do empreendimento. In: Encontro Nacional de Tecnologia no Ambiente Construído, 8, 2000, Salvador. Anais... Salvador: 2000.

[2] OWEN, D.D. Contrating-Out in a facilities management Context 1994. Doctoral Thesis, Dept. of Surveying, University of Stanford, Salford UK, 1994.

[3] KYMMELL, Willem. Building Information Modeling - Planning and Managing Construction Projects with 4D CDA and Simulations. Ebook. McGraw-Hill, 2008.

[4] TURBAN, Efraim et al. Business Intelligence: um enfoque gerencial para a inteligência do negócio. São Paulo: Bookman, 2009.

[5] KCAMETE, A.; AKINCI, B.; GARRET Jr, J. H. Potential utilization of building information models for planning maintenance activities. In: INTERNATIONAL CONFERENCE COMPUTING IN CIVIL AND BUILDING ENGINEERING, 2010, Nottingham. Proceedings... Nottingham: Nottingham University Press, p. 151-157

[6] MATTOS, ALDO DÓREA. Como preparar orçamentos de obras: dicas para orçamentistas, estudos de caso, exemplos -- São Paulo: Editora Pini, 2006 